\title{
PSYCHE.
}

\section{SOME OLD CORRESPONDENCE BETWEEN HARRIS, SAY, AND PICKERING.-I.}

[Many years ago Dr. J. L. LeConte entrusted to me some letters of Dr. T. W. Harris and Dr Charles Pickering, for use if I wished it in the Entomological Correspondence of Dr. Harris, then preparing. Most of them were written in the earliest period of their entomological studies, from Milton and from Salem, and in the discrimination that had then to be made from the great volume of correspondence, only one of them was used, (loc. cit., 25I), viz. one from Harris to Say, written from Milton in 1829. The others, however, are so interesting as showing the condition of entomology at a time when the numbers of its devotees in this country could easily be counted on one's fingers, and as revealing in some slight degree the temperament and character of the different writers that I have thought it worth while to reproduce them in Psyche, one at a time, that others may share the pleasure I have had in their perusal.

The letters proposed to be printed in this series are six from Dr. Harris and two from Dr. Pickering, all addressed to Say, together with the abbreviated draft of Say's replies, which, whenever such occur, were scribbled on the back of the writer's letters. They will be printed in chronological order, first five letters from Dr. Harris written between I823 and 1825 with Say's replies, then two from Dr. Pickering, both of I825, and finally the last of Dr. Harris's, of somewhat later date, in 1834 , the last from each of Say's correspondents bearing no reply. All are printed exactly as written, abbreviation, punctuation, and all, with an occasional memorandum of my own in brackets. The first of the series is given below with the reply. The others will follow under the above caption, from time to time as opportunity offers.—Samuel H. Scudder.]

[HARRIS TO SAY.]

Milton, (Mass.) July 7, I\$23.

To Thomas Say, Esqr.

Sir,

Though personally a stranger to you.I have taken the liberty of addressing you-and, in doing so, I have the permission of Mr. Nuttall to use his name as a password to admit me to your notice. An ardent love of Natural Science has induced me, though engaged in an arduous profession, to devote some of my leisure moments to the study of Botany \& Entomology; but the want of books, time. \& patience, has not permitted me to make any great proficiency. Permit me, Sir, respectfully to request your aid in this pursuit, so far, at least, as to answer some queries which I would propose to you. In May 1822 I accompanied an invalid to Philadelphia, but was hurried away by 
the nature of my patient's complaint, before I could obtain the honour of an introduction to you, a circumstance which I have greatly regretted ever since. I however saw Mr. Peale's museum, \& found that Mr. Titian Peale was making a collection of insects; among these I observed that which perforates the apple tree, known here as the apple-tree borer. This (which I presume to be of the Cerambyx family) I was informed had been described by you. Please inform me the name it has received, \& where I shall find your account of it. There is another insect very destructive to our Peach trees, boring around the trunk near the root, $\&$ which from the chrysalis (for I have not as yet obtained the perfect insect) must be the larva of a Cossus, or some other of the wood eating lepidopterous caterpillars. Length of the larva one \& a quarter inch (legs r6.) colour white, with a reddish tinge. Do you know it? The Locust tree is infested by a large species of this kind, which is described by Prof. Peck, in the Mass. Agricult. Papers, by the name of Cossus Robinia. This, as I have ascertained, also perforates the Black Oak (Quercus tinctoria Bart.). The Peach tree is subject to the attacks of a Buprestis, which perforates such branches as are old \& incline much. The name of the species I do not know. Length rather less than $\frac{1}{2}$ inch. Colour of the elytra dull brassy brown, with 3 or 4 irregular longitudinal lines. Abdomen above green ; below brilliant cupreous. I am particularly desirous to obtain information respecting our native species of Lytta, or Meloë. In Boston Lytta atrata Fabr. is sold for Lytta vittata; \& some of our Physicians have confounded $L$. cinerea under the same name vittata. This is not important in practice; but is so in nomenclature. Are not all three, together with Lytta marginata, of the genus Cantharis of De Geer, Geoffr., Oliv., Lamark, \& Latr., as defined by Leach in Brewster's Encyclopædia? What species have you in Pennsylvania? Are any kept by apothecaries for the purpose of vesication? By what names are they sold? On what plants are they principally found? At what times? And are they easily procured? Lytta atrata and cinerea are very common here : vittata and marginata I have seen in collections only: none others have I yet found. Do you know the ceconomy of these insects? Do the larvæ live and metamorphose in the earth? Any information, or reference to authors on the subject will be gratefully received. Illiger's Magazin I.256 has been quoted; but I have not the work to consult; if you have access to it, pray give me the substance of his account. It is my intention to draw up a description of these species, for some of our medical journals, in order to correct the mistakes in the names of the species, and your observations, if you will favour me with them, shall be duly acknowledged.

Has the moth from the apple-worm been described? and by what name? The gregarious caterpillar, which infests some trees in autumn, enclosing whole branches in a web, and devouring all but one membrane of the leaf, giving it 
the appearance of having been scorched by fire, is produced by a small white moth (genus Artica?) immaculate, and but little more than half an inch in length. What is the species? Can you give me the history of the common rosebug, Melolontha subspinosa? Fabr., or of the striped cucumber-bug? Chrysomela - ?

My collection of insects is small, containing but few more than 500 species, \& my professional avocations will not permit me to increase it much. If I have any species which could be acceptable to you, they are at your service. I have fine spec. of Pap. Troilus, Asterias, Plexippus, Idalia, \&c., Bombyx Cecropia, Polyphemus, Prometheus, with their cocoons, that of the latter being very curious. I have also Hemerobius cornutus, Pectini[c]ornis, \&c; many Hymenoptera, among which Leucospis dorsigera, Ichneumon pennator, the gall insect of the black oak \&c. Also several insects interesting as having been described by the late Prof. Peck. Such as Stenocorus putator Peckii, which prunes the branches of the oak; Rynchanus strobi Peckii, perforating the leading shoot of the white pine; Rynchanus cerasi Peckii, inhabiting the cherry and plum; Tenthredo cerasi, the cherry tree slug. I have hitherto pursued the study of Entomology without any other systematic work than Samouelle's little compendium; and, having very recently procured Fabricius, have not ascertained more than one tenth of the species in my collection. How deplorably ignorant I am you will therefore easily imagine-indeed it must be sufficiently apparent from this letter.

Accompanying this, is a little memoir, which was printed in the Agricultural Journal. The species described I have since found to answer tolerably to Bombyx acria Fabr.; the colour of the wings of the male however is not so dark, \& the ash-coloured female is not mentioned by Fabricius; \& though it may possibly prove to be the same insect, yet I think its identity could hardly have escaped the observation of Prof'r Peck. I confess that I am much more interested in the history of. such insects as appear to be injurious, or promise to be useful, than in the mere collection of such as are curious only.

A correspondence with you would be esteemed a great gratification $\&$ honour. I must rest my claim to your notice, principally, on the similarity of our pursuits, on my desire for information, \& on your ability to give it. Which if you do, it will greatly oblige, Sir,

Your humble serv't

T. WM. HARris.

Please address your reply to Thaddeus William Harris, M. D., Milton, Mass.

[DRAFT OF REPLY BY THOMAS SAY.]

The beginning of my reply was a copy of the answer to -

I shall endeavour to reply to y'r inquiries as well as time \& memory will permit. The apple borer I've desc'd under name Saperda 2-fasciata Melsh. The name however is a very bad one, inasmuch as the ins. is not banded, but ornamented w. 2 wh't long'l broad lines; notwith'g this as the name has b'n given 
and to my knowledge, I cannot stoop to the knavery of changing it. ${ }^{*}$ The publ'n of the paper will soon take place in the Journal, it was in fact in the press before I ret'd from N. W. [the Northwest]. The fact of the Peach tree being subject to the attacks of a Buprestis is altogether new to me. We have $2 \mathrm{sp}$. at least wh. agree w. y'r desc'n viz. femorata \& characteristica. The latter being rather larger than y'r mensuration $\&$ the thorax having elevated lines as well as the elytra I think it probable y'r depred'r is femorata wh. is orn'd w. 2 dull brassy irregular spots on ea. elytron more or less indistinct, but somet. obsolete.

The g's Lytta F. is certainly same w. Cantharis Oliv. \&c. The larvæ of the Cantharids live \& metam'e in the earth feeding on roots \&c, but for more inform'n I must refer you to Sonnini's Buffon Vol. 54, p. 395 ; also Olivier, Vol. 3. The no. of sp. already disc'd in the U. S. is 16 , viz. segmenta $\dagger$, vittata $\times$, marginata $\times$, atrata $\times$, Nuttallii $\dagger$, alloida $\dagger$, articularis $\dagger$, immaculata $\dagger$, aenea $\times$, polita, sphaericollis $\dagger$, maculata $\dagger$, ferruginae $\dagger$, cinerea $\times$, Afzeliana, reticulata†; of these those marked w. a $X$ inhab. this state, those marked w. a $\dagger$ have been desc'd by myself and will appear in the Journal. It is prob'e that nearly if not all of these sp. might be used w. effect

Personal Notes. - Mr. P. R. Uhler,one of the leading American entomologists, has recently been elected provost of the Peabody institute in Baltimore. Mr. Uhler will still retain the position of librarian which he has held for the past twenty-five years. It is not

\footnotetext{
*[He changed his mind, describing it in this very paper under the name of bivittata. It is the $S$. candida of Fabricius.]
}

in vessication. By far the finest sp. is the Nuttallii, wh., as well as 2 or 3 of the other sp. is somew't larger than vesicatoria \& more brilliant. On one occasion near Rocky M's. I saw this sp. in such nos. that I c'd have gathered a couple of quarts in $\frac{1}{2}$ an hour, but few were seen elsewhere, $\&$ but one occurred on last exped'n. Have not Illiger, nor moth of apple worm. Do not know wh. species of greg's caterp's you mean. Rose-bug is Mel. subspinosa F. and cucumber bug is Crioceris vittata F., but I know no more of their history than is familiar to every farmer. It w'd give me g't pleasure to see those ins. you mention desc'd by Peck. I have not met w. his desc'n.

The Peach Insect I desc'd sev'l months since for a paper by $\mathrm{Mr}$. Worth on this ins. under name of $A$. exitiosa. W'n this essay will be publ'd I do not know, it was read to the A. N. S. 6 or 8 months ago. The sexes are very diff't. I have b'n desc'g shells of U. S. \& w'd be much obliged to you for any sp's you may pick up on y'r coast. Land and fresh water shells also highly accept'e. I will be happy to send you the names should you wish it. Your salt marsh caterpillar is cert'y the B. acria F. and it is fig'd by Drury and also by Cramer under the name of $\mathrm{B}$. caprotina.

a little curious how many entomologists have held the position of librarian in the public institutions of this country.

We deeply regret to announce the death, on February 25, of Mr. Holmes Hinkley of Cambridge, one of the active members of the Club and an ardent student of our Lepidoptera. 

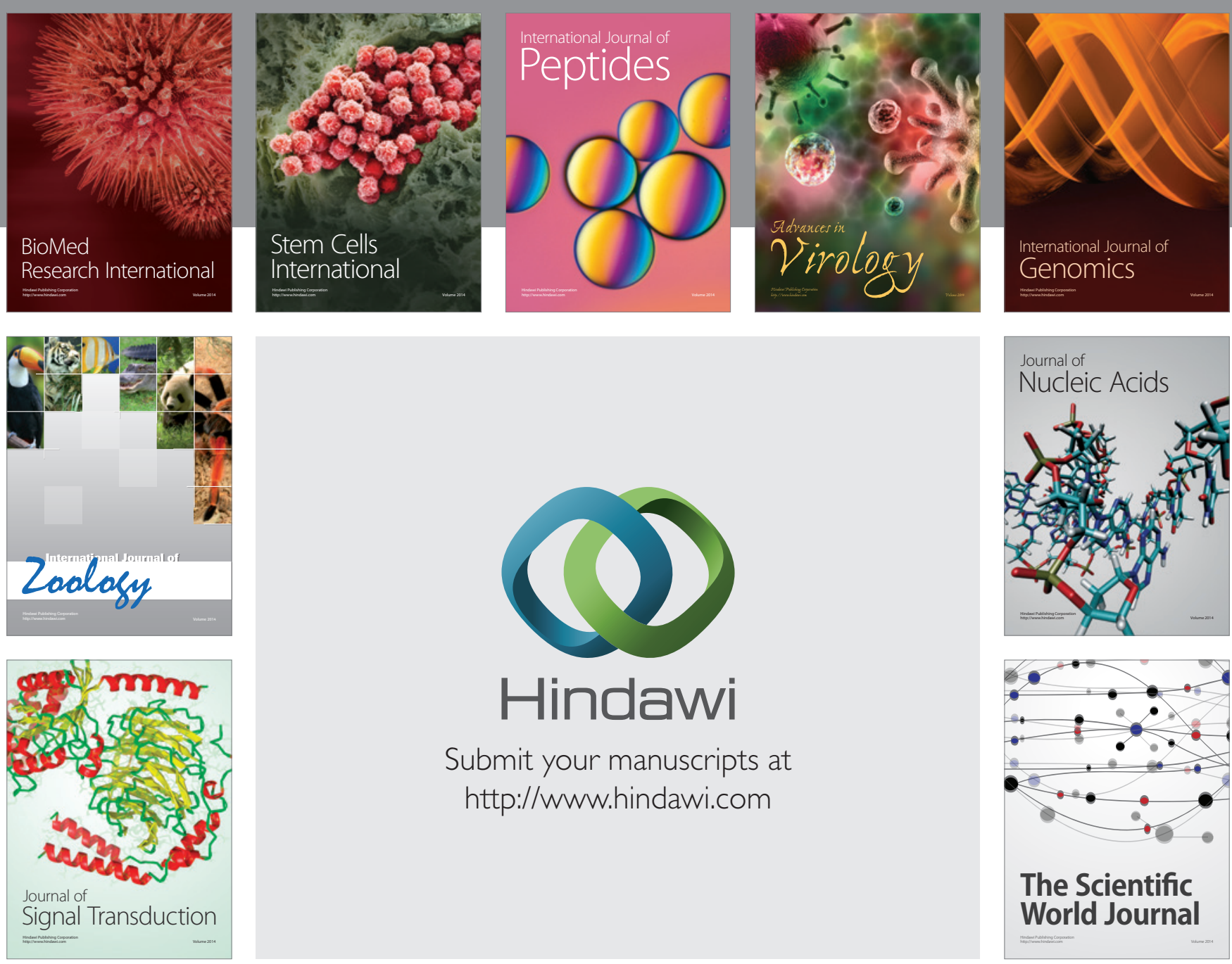

Submit your manuscripts at

http://www.hindawi.com
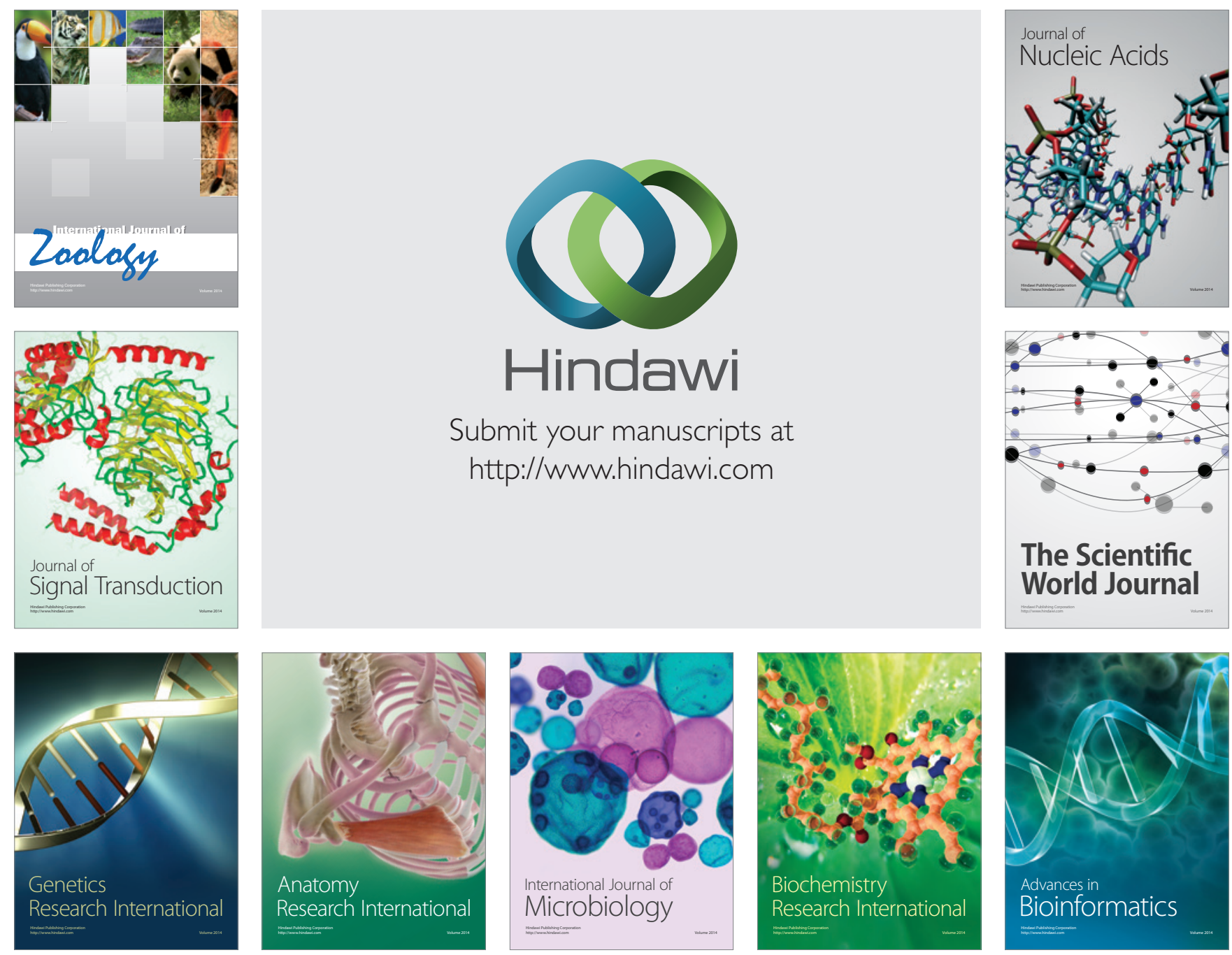

The Scientific World Journal
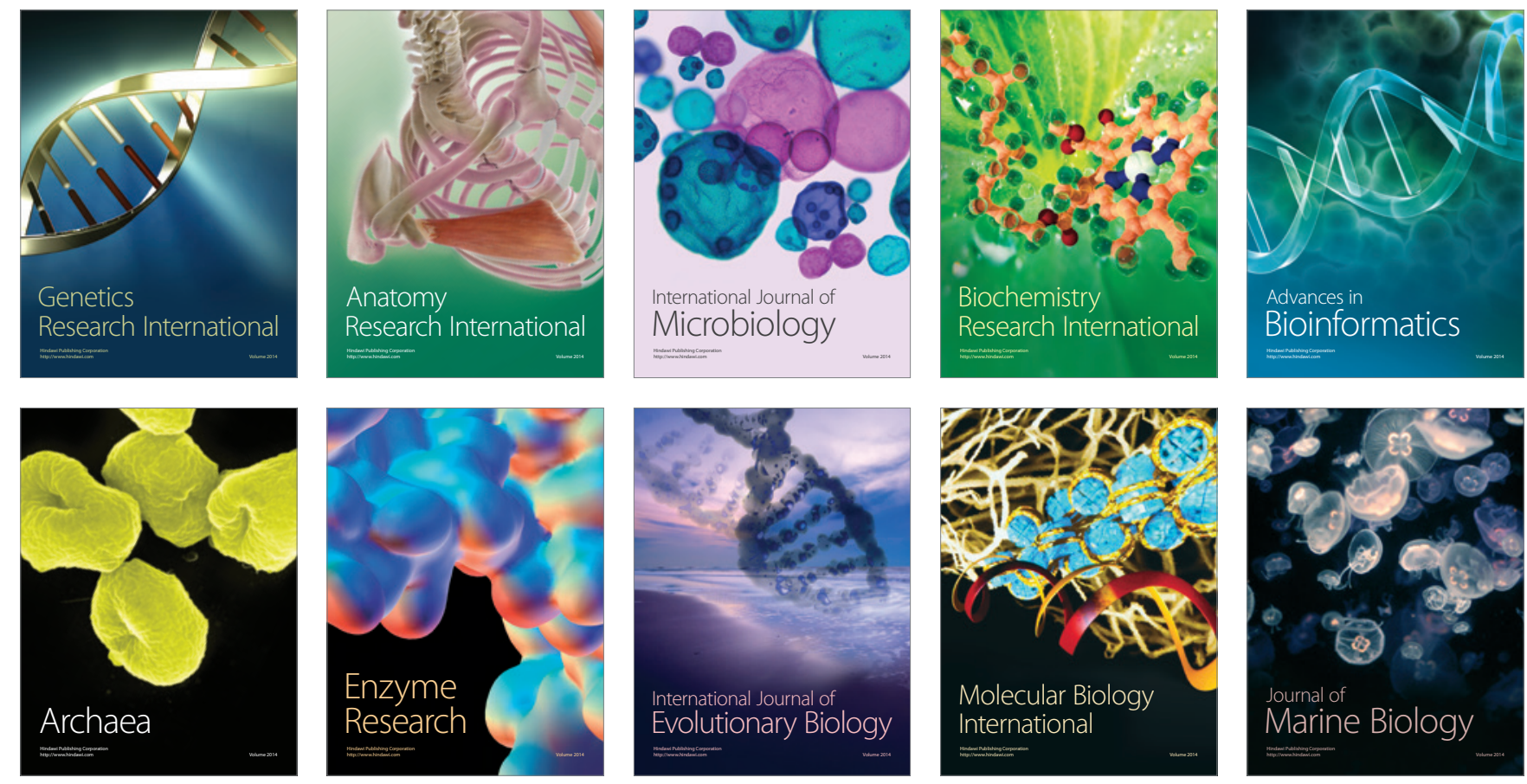